\title{
HISTORICAL STAGES OF THE DISTANCE EDUCATION DEVELOPMENT
}

\begin{abstract}
Olena Fidanian ${ }^{1}$
${ }^{1}$ postgraduate student, Private higher educational institution "Higher educational institution" "Interregional academy of personnel management, e-mail: fidanian@gmail.com, ORCID: https://orcid.org/0000-0002$1447-5926$
\end{abstract}

Abstract. In the context of the COVID-19 pandemic, the issue of transition of traditional education to distance learning. The study of the historical stages of development of distance education will contribute to a deeper understanding. The purpose of this article is to study the historical stages of development of distance education, as well as to establish the advantages and disadvantages of the introduction of distance education. The main methods used in the article are methods of historical analysis of scientific works on distance education, methods of comparative analysis and generalization. Currently, distance learning is becoming increasingly popular, as there is an increase in the number of people who want to get an education, but do not have the opportunity to do so in the form of full-time education. As a result it can be argued that the manifestation of MOOC as an education system is spontaneous and needs to be further refined. Today, distance education can only serve as a supplement to the traditional form, the most effective implementation will be a combination of these two models of education.

Keywords: distance education; historical stages of development of distance education; COVID-19 pandemic; educational institutions.

\section{JEL Classification: A20, H52}

Formulas: 0; fig.: 0; tabl.: 1; bibl.: 3

Introduction. In the context of the KOVID-19 pandemic, the issue of transition of traditional education to distance learning. The study of the historical stages of development of distance education will contribute to a deeper understanding.

Literature review. The question of the History of Distance Learning was studied quite deeply by Miller G. (2014), who clarified the main stages of the development of distance education from its inception to the beginning of the $21 \mathrm{st}$ century.

The main advantages of distance education in his work were studied by Aspillera M. (2010), who compared traditional education and distance learning.

The main issues regarding the adaptation of online learning to the needs of today were studied by Writers S. (2012), who proposed major changes in the forms and methods of traditional learning for the transition to distance learning.

Aims. The purpose of this article is to study the historical stages of development of distance education, as well as to establish the advantages and disadvantages of the introduction of distance education.

Methods. The main methods used in the article are methods of historical analysis of scientific works on distance education, methods of comparative analysis and generalization.

Results. The history of distance education dates back to the 1700s. In 1728, Caleb Phillips advertised in a Boston newspaper the recruitment of students to study shorthand anywhere in the country by exchanging letters. This was the beginning of distance education. 
Isaac Pitman made a huge contribution to the development of distance education. In 1840, he mailed letters to everyone with his lessons. The next were C. Toussaint and G. Lanchensteidt, who in 1856 founded the Institute of Correspondence Education in Berlin. The training was also conducted by sending letters with training material, tests, etc.

In 1873, the first distance learning schools in the United States were established. It is believed that Anna Eliot Tiknor founded the Tiknor Society for Women for the first time, students studied at a distance by mail. A year later, in 1874, Isaac Pittman proposed to create his own curriculum by mail.

Shortly afterwards, in 1892, the University of Chicago created the first distance learning program, thus becoming the first distance learning institution in the United States. From 1899 in Canada, the Royal University began to teach students at a distance.

In 1906, Calvert Elementary Schools in Baltimore also began teaching distance learning.

During the first half of the twentieth century, with the advent of new technologies, the process of distance education accelerated, it was offered in various formats and for a wide range of students. So, with the invention of radio, the process of developing distance learning has accelerated, new forms of work with students have become available. It is believed that the first university to introduce radio into education was Pennsylvania State University, in 1922. Shortly thereafter, in 1925, Iowa State University began offering study credits for five courses in radio broadcasting. And in 1934, the same university launched the world's first educational channel, which still operates today.

With the advent of television in the 1950s, television courses developed. Thus, by 1953, television broadcasting of the courses had become very common among universities in the United States and Europe.

In 1965, the University of Wisconsin introduced a large-scale educational program for physicians using a telephone teaching format. In 1968, it was possible to obtain an accredited diploma based on distance education at the University of Lincoln, Nebraska.

In the 1960s, distance education gained international recognition and began to develop actively with the support of UNESCO. In 1963, the Prime Minister of England G. Wilson announced the creation of an "ethereal university", which intended to unite all educational institutions using distance education. In 1969, the Open University was established in England. Today, this university is very popular, it enrolls over 200,000 students from different countries in various fields.

In 1970, a California working group was formed to develop television training courses. Later, an entire Coastline Community College organization was formed to offer educational films to universities, libraries, and public television channels. In 1976, the first "virtual college" was opened, which taught under the Coastline program. However, one technology quickly replaced another, and it was soon suggested that online courses be taught via satellite stations, at which time the Internet was laid.

Over time, computers began to be used for distance learning. Back in the 60's. IBM has developed a unique distance learning program, Coursewriter. It could be customized for different types of classes, and it was used at the University of Alberta from 1968 to the 1980s. on 17 different courses. 
With the invention of the Internet, humanity has taken another step forward in educational technology.

During the 80 's, real-time learning technologies were improved, gaining popularity among companies and educational institutions. In 1981, the Institute of Strategy and Management in the United States began developing a program of online courses. In 1985, Southeastern University offered accredited diplomas obtained through a system of online courses. In 1989, the University of Phoenix was launched, the training was conducted in real time.

Throughout the 1990s, educational institutions used a variety of distance learning technologies in both synchronous and asynchronous learning.

In 1992, the University of Michigan developed an individualized approach to online learning using a computer. In 1994, the university offered a virtual school of learning (VSS) to some of its psychology students. In addition, in 1994, a distance learning company in New Hampshire developed the CALCampus program, which provides the ability to teach, administer, and send materials exclusively over the Internet.

In 1997, Blackboard developed a standard platform for managing and delivering courses. Today, the company is a world leader in remote technologies, whose products are used by more than 10,000 organizations around the world.

In the 2000s, distance learning became dominant. The Internet system has improved, become more accessible, and distance education technologies have also developed. As a result, the number of universities using Internet technologies has increased.

Currently, distance learning is becoming increasingly popular, as there is an increase in the number of people who want to get an education, but do not have the opportunity to do so in the form of full-time education.

In the fall of 2011, professors at Stanford University, Sebastian Tran and Peter Norvig, launched an introductory online course on the basics of artificial intelligence. In turn, this opening of courses attracted more than 160,000 students from 190 countries who attended the courses via the Internet. A significant number of students eventually withdrew, but 23,000 of the most persistent completed the course. The success of Sebastian Tran has inspired other universities (Princeton, Pennsylvania, University of Michigan) to open their online courses. Next, scientists from Stanford, created Udacity a website, a powerful provider of online courses. The next step in the development of distance education is the opening of multifunctional mass online courses (MOOC) platforms that offer their students the curricula of different universities.

The main platforms of online courses. Udacity courses include video lectures, tests and homework. Videos last about five minutes or less.

Udacity stimulates the active position of the student, participation in the student, academic community, in particular, through the rating of activity. Publication of questions and help-consultation on forums is welcome. A forum is a place where students ask questions, help each other, express their attitude to the course, and can connect with other students to form study groups, organize real meetings for communication and joint learning.

Udacity has a softer registration policy and temporary learning characteristics. A distinctive feature of Coursera (courses are only available for certain periods of time) is the availability of courses, ie. lessons are available at any time after their release. There 
are deadlines within the course (you can watch the video at any time during the week, but at the end of the week you have to do your homework), but you can start the course at any time. This approach is welcomed by working listeners: the requirements should not be too strict.

Didactic features are shorter video clips. Video courses last 2 minutes, sometimes less, but not more than 6 minutes; if more - there are pauses for quizzes, tests, tests to make learning seem individual.

Also a distinctive positive feature is that Udacity can help the student find a job, as it forms a resume for each graduate and sends it to potential employers at will. The content of the resume is determined not only by the grade for the final exam, but also by the student's activity on the course. Another feature of Udacity is the great activity in finding sustainable business models.

In 2012, after the development of Udacity, two more companies, Coursera and MITx / EDX, began operating, offering their online courses at America's most prestigious universities.

The largest providers of online courses today are Coursera, EDX, Udacity.

The leader in MOOC is the Coursera project, formed by scientists from Stanford University. The portal has more than 400 courses from the best educational institutions in the world. As of 2014, the main part of the courses is presented in English, there are courses in Chinese, Spanish, French, Russian, Portuguese (more than a dozen), there are several courses in other languages. However, a company such as ABBYY Language Services is developing a special technology platform that allows volunteers to simultaneously translate subtitles to their favorite courses online. The project presents courses in various fields, such as physics, mathematics, humanities, medicine, information and economics, as well as business courses. The duration of the courses is up to ten weeks, the project offers full-fledged video lectures, text notes, homework, tests and final exams. A significant difference of existing online courses is that it is a true university education. It begins and ends on a certain day. Students watch videos weekly and do test assignments that need to be passed on time and get marks for them.

EDX is another large company that provides online courses. A nonprofit that was founded by professors at Harvard University, the Massachusetts Institute of Technology (MIT) and the University of Berkeley. EDX is headquartered in Cambridge, Massachusetts. The project is managed by MIT and Harvard. The training technology and methodology are almost the same as in other MEP projects. Lectures are divided into modules lasting about 10 minutes, alternating with exercises.

Some courses at EDX are built on unique software designed specifically for specific topics or teaching methods. Well-known IT companies are involved in the creation of courses, the software (software) of which is used in teaching students. Thus, a contract was signed with VMware Inc, as a result the company supplies its software for the Harvard course "Fundamentals of Computer Science". Students will have access to VMware Workstation 9 and VMware Fusion 5. This collaboration allows them to run various virtual programs on their computer, such as Linux, Windows and others.

Also, this platform can serve as a laboratory in which data will be collected to help understand how students learn.

Discussion. Based on the diversity of training, it is possible to formulate positive and negative characteristics from the MOOC (table 1). 
The positive and negative characteristics from the MOOC

Table 1

\begin{tabular}{|l|l|}
\hline \multicolumn{1}{|c|}{ The main benefits of MOOC } & The main disadvantages of the MOOC \\
\hline $\begin{array}{l}\text { 1. The proposed variety of programs and } \\
\text { courses. }\end{array}$ & 1. Mass of courses. \\
\hline 2. More loyal training costs. & 2. Problems with motivation \\
\hline 3. Comfortable learning conditions. & 3. Incomplete courses \\
\hline $\begin{array}{l}\text { 4. Closer interaction with teachers, } \\
\text { communication in open discussions on the site } \\
\text { and ample opportunities to focus }\end{array}$ & $\begin{array}{l}\text { 4. The quality of the evaluation system and the } \\
\text { quality of the proposed materials }\end{array}$ \\
\hline 5. Additional education & $\begin{array}{l}\text { 5. There is a lack of staffing for online courses } \\
\text { in the domestic education system }\end{array}$ \\
\hline 6. Advanced training & \\
\hline 7. Absence of any requirements &
\end{tabular}

Sourses: made on the basis of the following references: [2-3]

\section{The main benefits of MOOC.}

1. The proposed variety of programs and courses. Distance education offers a huge range of online courses, today every student can find any topic of interest to him, from agriculture to medicine.

2. More loyal training costs. Online programs are a more affordable learning option, as payment is much less. There is no need to visit educational institutions, spend on educational materials, all this is available thanks to the online time mode. In addition, many universities are starting to take loans for education through the MEP.

3. Comfortable learning conditions. Lecture and other material is provided to the student in electronic form, which is performed and sent back, ie. trips to the school are excluded, and assignments can be performed at any convenient time.

4. Closer interaction with teachers, communication in open discussions on the site and ample opportunities to focus. This is rather an advantage for shy and timid students, they are offered the opportunity to participate in surveys, suggestions, discussions of the learning process, discuss difficult material, etc. online, which is easier than in a class with the presence of other people. Some students also argue that it is easier to focus when studying MEP because you do not have to be distracted by other students. Another positive point is the manifestation of cooperation, ie students participate in discussions, exchange ideas, and thus begin to share their knowledge and experience.

5. Additional education. Students can work and study at the same time thanks to the MEP, improve their knowledge, which in turn affects their career growth.

6. Advanced training. There are ample opportunities to improve your skills in an existing profession or gain additional in-depth knowledge without leaving work.

7. Absence of any requirements. All you need to register is the Internet. There are also no restrictions on age, education, etc.

\section{The main disadvantages of the MOOC:}

1. Mass of courses. The ratio of teachers and students in all educational institutions should be proportional to ensure quality education for all students. The teacher has the opportunity to identify and work with weaker students within the university, the MEP system eliminates this, as a huge number of students enroll in online courses. It is not possible for full-time teachers to work with such a mass, to identify a weak and strong 
student is not possible, as a result of which students learn on their own, ie. there is no individual approach to the student.

2. Problems with motivation. There is no measure of penalties for incomplete training. A huge number of beginners drop out of training due to lack of motivation. Upon graduation from a traditional university, there is a prospect of future employment, and upon graduation, a certified diploma is issued. In case of failure to complete the study, the student faces expulsion without the issuance of any document. The following disadvantage follows from this problem.

3. Incomplete courses. According to statistics, about $90 \%$ of registrants do not complete the courses. This is because many people enroll in online courses out of curiosity, and eventually interest in learning dries up.

4. The quality of the evaluation system and the quality of the proposed materials. E-learning excludes practical and laboratory classes required to consolidate theoretical material. There are gaps in the evaluation that is performed by a computer, as a consequence - the problem of evaluating a huge number of scientific and creative works. There is no control over the acquired knowledge, students, answering test tasks or solving creative questions, often use additional materials, thus eliminating the selfexpression of their own thoughts and oral answers.

5. There is a lack of staffing for online courses in the domestic education system. Most teachers are not prepared for a more massive transition to e-learning, both professionally and morally.

All the imperfections of the MOOC stem from each other and are interconnected. If you solve the system of assessment and motivation, the problems of incomplete courses and mass are solved immediately.

The MOOC is currently a topic of discussion for the future of higher education. It is too early to say with confidence that online courses will completely replace traditional education. In order to be universally embedded in learning, MEPs need to improve. First of all, it is necessary to overcome the language barrier, to create courses that satisfy the world audience. The issue of certification and accreditation of knowledge acquired during the training of the MOOC remains unresolved. It follows from the above that the positive qualities of the MOOC are undoubtedly greater, but, like any new experimental technology, the MOOC must be tested over time.

Conclusions. In conclusion, it can be argued that the manifestation of MOOC as an education system is spontaneous and needs to be further refined. Today, distance education can only serve as a supplement to the traditional form, the most effective implementation will be a combination of these two models of education.

\section{References:}

1. Miller, G. (2014) History of Distance Learning. Education Guidance. American Inter Continental University Online. URL: http://www.worldwidelearn.com/education-articles/history-of-distancelearning.html

2. Aspillera, M. (2010) What Are the Potential Benefits of Online Learning? Education Guidance. WorldWideLearn. URL: http://www.worldwidelearn.com/education-articles/benefits-of-online-learning.htm. 3. Writers, S. (2012) 10 Advantages to Taking Online Classes. Open Education Database. URL: http://oedb.org/ilibrarian/10-advantages-to-taking-online-classes/. 